\title{
Cross-Sectional Survey
}

\section{Q Variations in Interlaminar Epidural Steroid Injection Practice Patterns by Interventional Pain Management Physicians in the United States}

Lisa Doan, MD, Hersh Patel, MD, Yeseniya Aronova, MD, and Christopher Gharibo, MD

From: Department of Anesthesiology, Perioperative Care and Pain Medicine, New York University Langone Health, New York,

Address Correspondence: Lisa Doan, MD Department of Anesthesiology, Perioperative Care and Pain Medicine New York University Langone Health 550 1st Avenue New York, NY 10016 E-mail:

lisa.doan@nyumc.org

Disclaimer: This work was funded by the Department of Anesthesiology, Perioperative

Care and Pain Medicine, New York University Langone Health, New York City, New

York.

Manuscript received: 03-28-2018 Revised manuscript received: 04-25-2018

Accepted for publication: 04-27-2018

Free full manuscript: www.painphysicianjournal.
Background: Previous surveys have identified variations in practice patterns related to epidural steroid injections. Since then, the United States Food and Drug Administration (FDA) has required the addition of drug warning labels for injectable corticosteroids. Updated evidence, as well as scrutiny from regulatory agencies, may affect practice patterns.

Objective: To provide an update on interlaminar epidural steroid injection (ILESI) practice patterns, we surveyed interventional pain management (IPM) physicians in the United States.

Study Design and Setting: This was a cross-sectional survey of IPM physicians in the United States.

Methods: A web-based survey was distributed to IPM physicians in the United States selected from the Accreditation Council for Graduate Medical Education accredited pain medicine fellowship program list as well as the American Society of Interventional Pain Physicians membership database. Physicians were queried about ILESI practices, including needle size, use of image guidance, level of injection, identification of the epidural space, and preference for injectate.

Results: A total of 249 responses were analyzed. All respondents used image guidance for ILESI There were variations in needle size, use of contrast, number of fluoroscopic views utilized, technique for identifying the epidural space, and choice of injectate.

Limitations: The response rate is a limitation, thus the results may not be representative of all United States IPM physicians.

Conclusions: Though all respondents used image guidance for ILESI, variations in other ILESI practices still exist. Since the closure of this survey, a multi-society pain workgroup published recommendations regarding ESI practices. Our survey findings support the need for more evidencebased guidelines regarding ESI.

Key words: Epidural injection, epidural steroids, survey, low back pain, neck pain, technique

Pain Physician 2018: 21:E493-E499 ow back and neck pain are important causes that lead to disability. Low back pain has an lestimated lifetime prevalence of $75-80 \%$ of the population (1). Neck pain has an estimated lifetime prevalence of $50 \%$ (2). Interlaminar epidural steroid injection (ILESI) is a commonly employed interventional procedure used to manage chronic, painful spinal conditions. In the interlaminar technique, injection to the epidural space is fperformed between 2 adjacent lamina. The main goal of ESI is to facilitate therapy by reducing pain with the added benefit of potentially limiting opioid consumption (3). In systematic reviews, ESIs were associated with short-term improvement in pain intensity and function for lumbar 
radiculopathy (4-6). Similar results have been found in the cervical spine (7). Combining cervical ESIs with conservative measures provides superior outcomes to either treatment method alone (8). It is believed that these injections provide relief via anti-inflammatory, irrigative and neuromodulatory effects (9). In order to accomplish this, medication should be delivered as close to the targeted area as possible. The addition of fluoroscopy to the interlaminar epidural approach has allowed for more precise delivery of the medication to the epidural space and reduced procedure-related complications (10).

Despite the fact that ESIs have been used for decades, there is no consensus among physicians on the peri-procedural standards, technical approach or effective injectate. A survey from Cluff et al (11) found there is varying practice on almost every technical aspect of ESIs, including the use of fluoroscopy, patient position, and choice of injectate.

Though generally safe, there have been rare instances of catastrophic injuries associated with ESIs. Since the publication of the Cluff et al (11) survey, the label for triamcinolone was updated in 2011 indicating it was not for epidural use. In April 2014 the United States Food and Drug Administration (FDA) required the addition of a warning to drug labels for injectable corticosteroids describing the risks of rare, but serious, neurologic events, including stroke, paralysis, and death (12). The FDA coordinated a multi-society pain workgroup (MPW) to develop recommendations to minimize risks with ESIs, but consensus was not reached on all suggestions, and the FDA itself has not modified its initial warning based on feedback from the MPW.

The purpose of this study was to identify ILESI practice patterns among United States pain physicians and expound upon previous examinations.

\section{Methods}

This study was approved by the Institutional Review Board of our institution.

\section{Survey}

A 22-item questionnaire was created to obtain information about practice patterns related to ESIs. The survey included open-ended and closed-ended questions. Results regarding peri-procedure monitoring and transforaminal epidural steroid injection practices have been previously submitted for publication. This manuscript focuses on specific practices related to ILESI (Appendix I).

\section{Study Patients}

Patients were interventional pain management (IPM) physicians in the United States. A survey link was sent to 1,800 IPM physicians selected from the Accreditation Council for Graduate Medical Education accredited pain medicine fellowship program list as well as the American Society of Interventional Pain Physicians membership database.

\section{Data Collection}

Survey data were collected and stored in a password protected account using the online survey service company Survey Monkey (San Mateo, CA). After the initial e-mail link was sent, reminder emails were sent at 1, 2, 3, and 4 weeks. A final e-mail reminder was sent out 4 months later. Completion of the survey was voluntary. Only the principal investigator and actively involved researchers had access to the data. Data were collected between October 28, 2014, and April 2, 2015.

\section{Analysis}

Survey responses were analyzed using Survey Monkey and Excel software with frequency analysis.

\section{Results}

\section{Demographics}

There were 249 IPM physicians who responded to the survey, yielding a $13.8 \%$ response rate. Of the respondents, $73 \%$ worked in private practice, $21 \%$ in academics, $2 \%$ in a government hospital, and $4 \%$ other, including hospital employment. Of the 238 who reported primary specialty, $69 \%$ had an anesthesiology background and $24 \%$ had a background in physical medicine and rehabilitation. Other specialties represented were psychiatry, radiology, neurosurgery, and orthopedics.

Respondents had been performing ESIs for a median of 15 years (IQR 9-24 years). For those who perform cervical ILESI, the median number performed per month was 20 (IQR 10-30). For those who perform lumbar ILESI, the median number performed per month was 30 (IQR 10-50). For those performing caudal ESI, the median done per month was 10 (IQR 5-20). 


\section{Injection Practices}

Regarding needle size, for cervical ILESI, 20 gauge (G), $18 \mathrm{G}$, and $17 \mathrm{G}$ needles were preferred $(52.4,30.9$, and $9 \%$ of respondents, respectively). Less commonly preferred sizes included $22 \mathrm{G}, 19 \mathrm{G}$, and $16 \mathrm{G}$ needles. Similarly, for lumbar ILESI, 20 G, 18 G, and $17 \mathrm{G}$ needles were preferred $(44.7,35.7,8.9 \%$ of respondents, respectively). There was a wider range of less preferred needle sizes, from $15 \mathrm{G}$ to $27 \mathrm{G}$ needles. For caudal ESI, $22 \mathrm{G}, 20$ $\mathrm{G}$, and $18 \mathrm{G}$ needles were preferred $(36.6,20.9,20 \%$ of respondents, respectively). There was a wide range of less preferred needle sizes, from $16 \mathrm{G}$ to $27 \mathrm{G}$ needles.

Of those who responded to questions regarding image guidance, all used image guidance for cervical ILESI and lumbar ILESI. The percentage of respondents who used particular views is listed in Table 1. Anteroposterior (AP) views were used by the majority of respondents. For cervical ILESI, $69.6 \%$ of respondents used more than one view all the time. For lumbar ILESI, $44.2 \%$ of respondents used more than one view all the time. Contrast was used $100 \%$ of the time by 73.8 and $69.1 \%$ of respondents for cervical and lumbar ILESI, respectively. Contrast was used selectively by 21.9 and $27.1 \%$ of respondents for cervical and lumbar ILESI, respectively. Contrast was not used by 4.3 and $3.8 \%$ of respondents for cervical and lumbar ILESI, respectively. Live fluoroscopy was used all the time by 70.9 and $62.5 \%$ of respondents for cervical and lumbar ILESI, respectively. Live fluoroscopy was used selectively by 15.2 and $18.8 \%$ of respondents for cervical and lumbar ILESI, respectively. Live fluoroscopy was not used by 13.9 and $18.7 \%$ of respondents for cervical and lumbar ILESI, respectively. For cervical ILESI, $59.4 \%$ of respondents always used contrast in combination with live fluoroscopy. For lumbar ILESI, $52.1 \%$ of respondents always used contrast in combination with live fluoroscopy. The majority of respondents preferred the loss of resistance technique to identify the epidural space for both cervical and lumbar ILESI. Hanging drop was the second most common technique utilized to confirm the epidural placement. Other preferences are listed in Table 2.

Regarding level of injection for cervical ILESI, 19.8\% of respondents always perform the injection at C7-T1; $63.3 \%$ of respondents always perform at either $\mathrm{C6-7}$ or C7-T1. A small percentage of respondents will sometimes perform ILESI at higher levels (C5-6 33.3\%, C4-5 $12.7 \%$, and C3-4 $8 \%$ of respondents).

Preferences for injectate solution are listed in Tables 3 and 4. For local anesthetics, the most commonly
Table 1. Percentage of respondents who use view $100 \%$ of the time.

\begin{tabular}{|l|c|c|}
\hline & $\begin{array}{c}\text { Cervical ILESI } \\
(\mathbf{n}=\mathbf{2 3 7})\end{array}$ & $\begin{array}{c}\text { Lumbar ILESI } \\
(\mathbf{n}=\mathbf{2 4 0})\end{array}$ \\
\hline AP & 89 & 90 \\
\hline Lateral & 36.2 & 50.4 \\
\hline CLO & 27 & 9.6 \\
\hline AP only & 6.8 & 3.8 \\
\hline AP + lateral only & 35 & 26.2 \\
\hline AP + CLO only & 26.6 & 9.6 \\
\hline AP + lateral + CLO & 8 & 4.6 \\
\hline
\end{tabular}

ILESI = interlaminar epidural steroid injection; $\mathrm{AP}=$ anteroposterior; $\mathrm{CLO}=$ contralateral oblique.

Table 2. Percentage of respondents that prefer each technique for identifying epidural space.

\begin{tabular}{|l|c|c||}
\hline & $\begin{array}{c}\text { Cervical ILESI } \\
(\mathbf{n = 2 3 5})\end{array}$ & $\begin{array}{c}\text { Lumbar ILESI } \\
(\mathbf{n}=\mathbf{2 4 2})\end{array}$ \\
\hline Loss of resistance & 87.2 & 93.4 \\
\hline Hanging drop & 8.1 & 0.8 \\
\hline Fluid column & 1.3 & 1.7 \\
\hline Fluoroscopy only & 3.4 & 4.1 \\
\hline
\end{tabular}

ILESI = interlaminar epidural steroid injection

Table 3. Percentage of respondents that prefer each local anesthetic in injectate.

\begin{tabular}{|l|c|c|c|}
\hline & $\begin{array}{c}\text { Cervical } \\
\text { ILESI } \\
(\mathbf{n}=\mathbf{2 3 7})\end{array}$ & $\begin{array}{c}\text { Lumbar } \\
\text { ILESI } \\
(\mathbf{n = 2 4 0 )}\end{array}$ & $\begin{array}{c}\text { Caudal } \\
(\mathbf{n}=\mathbf{2 3 7})\end{array}$ \\
\hline Bupivacaine & 19.8 & 35 & 40.1 \\
\hline Lidocaine & 30.4 & 39.6 & 38 \\
\hline Ropivacaine & 2.5 & 2.9 & 3 \\
\hline None & 46 & 21.7 & 18.1 \\
\hline Other & 1.3 & 0.8 & 0.8 \\
\hline
\end{tabular}

ILESI = interlaminar epidural steroid injection

Table 4. Percentage of respondents that prefer each steroid in injectate.

\begin{tabular}{|l|c|c|c|}
\hline & $\begin{array}{c}\text { Cervical } \\
\text { ILESI } \\
(\mathbf{n = 2 3 6 )}\end{array}$ & $\begin{array}{c}\text { Lumbar } \\
\text { ILESI } \\
(\mathbf{n}=\mathbf{2 3 8})\end{array}$ & $\begin{array}{c}\text { Caudal } \\
(\mathbf{n}=\mathbf{2 4 1})\end{array}$ \\
\hline Betamethasone & 25 & 15.6 & 16.6 \\
\hline Dexamethasone & 24.6 & 10.5 & 9.6 \\
\hline Methylprednisolone & 33.9 & 50.4 & 50.6 \\
\hline Triamcinolone & 15.6 & 22.7 & 22 \\
\hline No steroid & 0.9 & 0.8 & 1.2 \\
\hline
\end{tabular}

ILESI = interlaminar epidural steroid injection 
preferred agents are none for cervical ILESI (46\% of respondents), lidocaine for lumbar ILESI (39.6\%), and bupivacaine for caudal ESI $(40.1 \%)$. For steroid, the most commonly preferred agent was methylprednisolone $(33.9,50.4$, and $50.6 \%$ of respondents for cervical, lumbar, and caudal ESI, respectively).

\section{Discussion}

This survey provides an update on ILESI practice patterns among United States IPM physicians and elucidates the variations in practice that still exist to date.

\section{Injection Practices}

In 2002, Cluff et al (11) noted that approximately $49 \%$ of practices used fluoroscopy for ESI. In comparison, all practitioners in this survey use image guidance for ILESI which aligns with recommendations put forth by several societies (13). A majority of physicians use multiple views for cervical procedures, with $69.6 \%$ of respondents using more than one view all the time. For lumbar ILESI, $44.2 \%$ of respondents used more than one view all the time. In our survey contrast was used by 95.7 and $96.2 \%$ of respondents when performing cervical and lumbar ILESI, respectively. In comparison, in the Cluff et al (11) survey from 2002, $94 \%$ of practices routinely used contrast for ILESI and $6 \%$ did not. Cluff et al (11) noted that $91.8 \%$ of practices in 2002 reported using the loss of resistance technique to identify the epidural space. Although the overall use of loss or resistance remains about the same $(90.3 \%$ in our study), use of "hanging drop" for cervical ESI has decreased significantly compared to 2002 (8.1\% of individual respondents compared to $52.7 \%$ of practices in 2002) (11).

Our survey found that $36.7 \%$ of respondents sometimes perform cervical ILESIs higher than the C7-T1 or C6-C7 level. It has been recommended that cervical ILESI not be performed above the C6-7 level (13). This recommendation is noted to be based on the anatomical gaps in the ligamentum flavum and the smaller epidural space in the cervical area, but not from complications during the procedure itself $(13,14)$.

Use of local anesthetics for cervical procedures was noted to be none for $46 \%$ of interventionalists likely because cervical local anesthetic administration creates a high risk of profound cardiovascular effect and anes- thesia if inadvertently injected in the intrathecal space (15). In comparison, $57.5 \%$ of practice respondents in the survey performed by Cluff et al (11) in 2002 were still using local anesthetics in cervical ESI; 3.8\% of these practices were using solely local anesthetic. Lidocaine and bupivacaine are still commonly used for lumbar and caudal ESIs, respectively, with lower risks of intrathecal complications.

Epidural steroid practices have been under significant scrutiny since the labeling for triamcinolone was updated in 2011 stating it was not for epidural use followed by the announcement in 2014 that injectable corticosteroids should carry a warning label about serious adverse events. Even with the label indicating triamcinolone is not for epidural use, practitioners continue to use this steroid for ILESI (3rd most common for cervical, 2nd most common for lumbar and caudal). In our study, we found that most practitioners use the particulate steroid methylprednisolone in $33.9 \%$ cervical, $50.4 \%$ lumbar, and $50.6 \%$ caudal injections. The nonparticulate steroid, dexamethasone, is more commonly used in cervical interlaminar ESIs (24.6\% versus $10.5 \%$ and $9.6 \%$ for lumbar and caudal ESI, respectively).

One of the major limitations to the study was the low response rate of $13.8 \%$. Thus the results may not be representative of all IPM physicians in the US. The questionnaire was kept brief to improve participation in the survey, which limited the collection of valuable details including the rationale behind practice methods and policies.

Recommendations from the MPW were published shortly after final collection of responses for this survey (13). Nonetheless, interventionalists seemed to be trending towards recommendations set forth by the MPW. Our survey focuses predominantly on injection practices, which include needle size, use of image guidance, level of injection, identification of the epidural space, and preference for injectates. This study elucidates the discrepancies that still exist amongst the practitioners who perform these injections. As the MPW recommendations were published after completion of this survey, future surveys could re-assess ESI practice patterns. More evidence-based guidelines need to be developed to improve the efficacy and safety of these procedures. 
Appendix 1: ILESI survey questions.

Please only complete this survey if you perform epidural steroid injections.

What is the practice setting in which you perform interventional procedures?

- Academic

- Private Practice

○ Government Hospital (e.g., VA)

O Other (please specify)

How many years have you been performing epidural steroid injections?

On average, how many epidural steroid injections of each type do you perform monthly?

Cervical interlaminar

Lumbar interlaminar

Caudal

What gauge needle do you prefer for the following techniques?

Cervical interlaminar

Lumbar interlaminar

Caudal

What percent of the time do you use the following during performance of cervical interlaminar epidurals?
AP view
Lateral view
Contralateral oblique
Contrast
Live fluoroscopy
Catheter to injection medications

What percent of the time do you use the following during performance of lumbar interlaminar epidurals?

AP view

Lateral view

Contralateral oblique

Contrast

Live fluoroscopy

Catheter to injection medications

What is your preferred technique to identify the epidural space when performing a cervical interlaminar epidural?

- Loss of resistance

- Hanging drop

- Fluid column

○ Fluoro only

What is your preferred technique to identify the epidural space when performing a lumbar interlaminar epidural?

- Loss of resistance

- Hanging drop

- Fluid column

○ Fluoro only

What percent of cervical interlaminar ESIs that you perform are at the following levels?

$\mathrm{C} 3-4$

C4-5

C5-6

C6-7

C7-T1 
Appendix 1 (cont.): ILESI survey questions.

Which steroid do you routinely inject for cervical interlaminar epidural?

- Betamethasone (Celestone)

- Methylprednisolone (DepoMedrol)

- Triamcinolone (Kenalog)

- Dexamethasone (Decadron)

- No steroids are injected

Which steroid do you routinely inject for lumbar interlaminar epidural?

○ Betamethasone (Celestone)

- Methylprednisolone (DepoMedrol)

- Triamcinolone (Kenalog)

- Dexamethasone (Decadron)

- No steroids are injected

Which steroid do you routinely inject for caudal epidural?

- Betamethasone (Celestone)

- Methylprednisolone (DepoMedrol)

- Triamcinolone (Kenalog)

- Dexamethasone (Decadron)

- No steroids are injected

What local anesthetic do you routinely inject in the epidural space for cervical interlaminar epidural?

○ Bupivacaine

- Lidocaine

- Mepivacaine

- Ropivacaine

○ None

O Other

What local anesthetic do you routinely inject in the epidural space for lumbar interlaminar epidural?

- Bupivacaine

- Lidocaine

- Mepivacaine

- Ropivacaine

○ None

O Other

What local anesthetic do you routinely inject in the epidural space for caudal epidural?

- Bupivacaine

- Lidocaine

- Mepivacaine

- Ropivacaine

- None

O Other 


\section{References}

1. Iannuccilli JD, Prince EA, Soares GM. Interventional spine procedures for management of chronic low back paina primer. Semin Intervent Radiol 2013; 30:307-317.

2. Cohen SP. Epidemiology, diagnosis, and treatment of neck pain. Mayo Clin Proc 2015; 90:284-299.

3. Leem JG. Epidural steroid injection: A need for a new clinical practice guideline. Korean J Pain 2014; 27:197-199.

4. Chou R, Hashimoto R, Friedly J, Fu R, Bougatsos C, Dana T, Sullivan SD, Jarvik J. Epidural corticosteroid injections for radiculopathy and spinal stenosis: A systematic review and meta-analysis. Ann Intern Med 2015; 163:373-381.

5. Kaye AD, Manchikanti L, Abdi S, Atluri S, Bakshi S, Benyamin R, Boswell MV, Buenaventura $\mathrm{R}$, Candido KD, Cordner HJ, Datta S, Doulatram G, Gharibo CG, Grami V, Gupta S, Jha S, Kaplan ED, Malla Y, Mann DP, Nampiaparampil DE, Racz G, Raj P, Rana MV, Sharma $M L$, Singh V, Soin A, Staats PS, Vallejo R, Wargo BW, Hirsch JA. Efficacy of epidural injections in managing chronic spinal pain: A best evidence synthesis. Pain Physician 2015; 18:E939-E1004.

6. Sharma AK, Vorobeychik Y, Wasserman $\mathrm{R}$, Jameson J, Moradian M, Duszynski B, Kennedy DJ, Standards Division of the Spine Intervention Society. The ef- fectiveness and risks of fluoroscopically guided lumbar interlaminar epidural steroid injections: A systematic review with comprehensive analysis of the published data. Pain Med 2017; 18:239-251.

7. Manchikanti L, Nampiaparampil DE, Candido KD, Bakshi S, Grider JS, Falco FJ, Sehgal N, Hirsch JA. Do cervical epidural injections provide long-term relief in neck and upper extremity pain? A systematic review. Pain Physician 2015; 18:39-6o.

8. Cohen SP, Hayek S, Semenov Y, Pasquina PF, White RL, Veizi E, Huang JH, Kurihara C, Zhao Z, Guthmiller KB, Griffith SR, Verdun AV, Giampetro DM, Vorobeychik Y. Epidural steroid injections, conservative treatment, or combination treatment for cervical radicular pain: $A$ multicenter, randomized, comparativeeffectiveness study. Anesthesiology 2014; 121:1045-1055

9. Botwin KP, Gruber RD. Lumbar epidural steroid injections in the patient with lumbar spinal stenosis. Phys Med Rehabil Clin N Am 2003; 14:121-141.

10. Benyamin RM, Manchikanti L, Parr AT Diwan S, Singh V, Falco FJ, Datta S, Abdi $S$, Hirsch JA. The effectiveness of lumbar interlaminar epidural injections in managing chronic low back and lower extremity pain. Pain Physician 2012; 15: $\mathrm{E}_{3} \mathrm{C}_{3}-\mathrm{E}_{4} \mathrm{O} 4$
11. Cluff R, Mehio AK, Cohen SP, Chang Y, Sang CN, Stojanovic MP. The technical aspects of epidural steroid injections: A national survey. Anesth Analg 2002; 95:403-408.

12. US Food and Drug Adminstration. FDA Drug Safety Communication: FDA requires label changes to warn of rare but serious neurologic problems after epidural corticosteroid injections for pain, 2014. Available from: www.fda.gov/ Drugs/DrugSafety/ucm394280.htm. Accessed January 18, 2018.

13. Rathmell JP, Benzon HT, Dreyfuss P, Huntoon M, Wallace M, Baker R, Riew $\mathrm{KD}$, Rosenquist RW, Aprill C, Rost NS, Buvanendran A, Kreiner DS, Bogduk N, Fourney DR, Fraifeld E, Horn S, Stone J, Vorenkamp K, Lawler G, Summers J, Kloth D, O'Brien D, Tutton S. Safeguards to prevent neurologic complications after epidural steroid injections: Consensus opinions from a multidisciplinary working group and national organizations. Anesthesiology 2015; 122:974-984.

14. Manchikanti L. Cervical epidural steroid injection with intrinsic spinal cord damage. Spine (Phila Pa 1976) 1999; 24:1170-1172.

15. Schneider BJ, Maybin S, Sturos E. Safety and complications of cervical epidural steroid injections. Phys Med Rehabil Clin N Am 2018; 29:155-169. 
